\title{
Análisis del proceso migratorio de las familias colombianas en España
}

\section{Analysis of the migration process of Colombian families in Spain}

\author{
Adelina Gimeno Collado, María Josefa Lafuente Benaches y Francisco González Sala \\ Departamento de Psicología Evolutiva y de la Educación. Universidad de Valencia, España
}

Disponible online 30 de abril de 2014

\begin{abstract}
Se analiza la migración como proceso centrado en la familia transnacional, según relato de sus protagonistas: migrantes - padres e hijos - y familiares en Colombia. Se parte del modelo sistémico y de la metodología de la GroundedTheory. El proceso se desencadena por una combinación de factores de empuje y de llamada; los pioneros, mayoritariamente mujeres, poseen un perfil muy variado. Destaca la dificultad de sus primeras experiencias, que mejoran gracias a sus apoyos externos y a su tesón. A pesar de las dificultades del proceso de aculturación, el balance realizado es positivo, sobre todo por la esperanza puesta en los hijos, que tras las dificultades iniciales desean permanecer en España. Los hijos viven las peculiaridades de su propio proceso, pero no hay conflictos que deriven de sus diferentes niveles de aculturación. Todos anhelan una mayor acogida española, aunque agradecen los apoyos recibidos. Las metas y el progreso se producen en el ámbito privado: la familia, pero faltan, tanto la conciencia de grupo, como una acción social conjunta; tampoco hay proyectos para mejorar el entorno de origen o para mejorar la integración en el país de destino.
\end{abstract}

Palabras clave: Familias Transnacionales; Aculturación; Grounded-Theory; Proceso Migratorio.

This study analyses migration as a process centred on the transnational family as told by its main characters: migrants - parents and children $-\neg$ and their families in Colombia. The study is based on the systematic model and methodology of the Grounded Theory approach. The migration process is triggered by a combination of push and pull factors. The pioneers, mainly women, have very diverse profiles. We highlight the difficulty of their first experiences, which they overcome via personal tenacity and external support. Despite the difficulties of the acculturation process, the overall outcome is positive, especially regarding their expectations for their children, who wish to stay in Spain having overcome the initial challenges of adaptation. Children experience their own acculturation process, but there is no conflict between children and parents despite their different acculturation levels. Despite hopes that their integration process Spain would have been better, they are thankful for the support received. Decisions are made and adaptation occurs in the private domain, i.e., the family; however, there is a lack of group awareness or joint social action to improve conditions in the country of origin or to improve integration in the host country.

Key words: Transnational Families; Acculturation; Grounded-Theory; Migratory Process.

\footnotetext{
Correspondencia: Adelina Gimeno Collado. Dpto. Psicología Evolutiva y de la Educación. Universidad de Valencia. Avda. Blasco Ibáñez, $21,46010$. FAX (963864671). E-mail: Adelina.Gimeno@uv.es. E-mail de los otros autores: Mª. Josefa Lafuente Benaches: maria.j.lafuente@uv.es., Francisco González Sala: Francisco.Gonzalez-Sala@uv.es Esta investigación ha sido financiada por el Centro de estudios sobre inmigración CeiMigra, Valencia.
} 
Los movimientos migratorios recientes tienen unas características propias. Además del estrés generado por la separación familiar y el proceso de aculturación, se significan por la pluralidad - variados perfiles de las personas que emigran- y la feminización - las mujeres toman mayoritariamente la iniciativa - (Pedone, 2006; Soriano, 2006).

La feminización aparece asociada a condiciones laborales inferiores a las de los varones migrantes. Junto a aquellas que acuden a satisfacer la demanda internacional de cuidadoras, dando lugar a la "fuga de cuidados" (Bettio, Simonazzi, Solinas y Villa, 2004) y a la transferencia transnacional del trabajo reproductivo (Pedone, 2005), otras van a reunirse en el país receptor con los hijos para ayudarles con su prole, y también hay quienes huyen de relaciones opresivas (Sorensen, 2005), o se prostituyen. La mujer vive muchas veces la migración a través de los hijos - ellos influyen en todas sus decisiones- y el trabajo conseguido resulta decisivo en su proceso "emancipatorio e igualitario" (Soriano, 2006).

La migración conlleva altos niveles de estrés (Martín Fernández, 2006) asociados a pérdidas - de estatus, de estilo de vida, posesiones, relaciones, modelos de rol, identidad, pasado que no fue y pasado que fue (Pollock y Van Reken, 1999) y ajustes a la nueva vida (Nette y Hayden, 2007); además, la pérdida es ambigua por su inconclusión y por la vulnerabilidad derivada del estrés relacional (Falicov, 2007).

Aunque la migración no debería ser necesariamente estresante, si se cuenta con cierta semejanza cultural y con la tolerancia del país de llegada (Araujo, 1996; Escobar y Vega, 2000), la mayoría de estudios realizados en el contexto español detectan que el proceso está plagado de tensiones y dificultades, de deficiencias en las políticas y mecanismos institucionales. (Achotegui, 2008; Henao, 2008; Soriano, 2006). De ahí la importancia de fomentar las políticas sociales de acogida (Dovidio, Gaerter y Validwzic, 1998; Wolsko, Park, Judd y Wittenbrink, 2000). El estrés disminuye si se resuelven algunos hitos cruciales: trabajo digno, permiso de residencia, reunificación familiar, y si existen redes de apoyo (Parella, 2007; Sluzki, 1996) tanto en el país de origen como en el de acogida (Soriano, 2006).

La comprensión del proceso migratorio requiere además considerar el contexto y la relación dialéctica entre las fuerzas de empuje y de llamada (Herrera, 2003; Soriano, 2006), siendo la combinación sinérgica de ambas la que configurará el proyecto. El factor económico es fundamental, especialmente en las clases con menos recursos (Parella, 2007), aunque se articula con otros, como la ideología, la red migratoria previa y la historia de ambas comunidades (Colectivo Ioé, 2002).

El inmigrante se debate entre dos realidades culturales a armonizar: unos acaban relegando su cultura de origen, otros se resisten a las nuevas influencias, y otros logran mejores niveles de ajuste personal y social integrando ambas culturas - doble aculturación- (Berry, 1998; Castella, 2003). Los niveles de aculturación varían en función de cada elemento cultural (Eisikovits, 2000; Martínez, Paterna, López y Martínez, 2007) y según se trate del ámbito público o privado (Magaña,
De la Rocha, Amse y Magaña, 1996). Además, cada individuo y cada generación siguen su propio ritmo: los más jóvenes asimilan la cultura de acogida con mayor rapidez, y de esa diferencia surgen conflictos intrafamiliares (Portes y Zhou, 1993).

Se ha adoptado una perspectiva centrada en la familia transnacional, porque la migración implica a la familia completa. Todos sus miembros elaboran el proyecto migratorio y contribuyen a que se realice para mejorar la vida de todos (Masanet, 2008). La familia actúa como sufridora y como beneficiaria, y sobre todo, como un sistema de protección ante el estrés del migrante (Walker, Wingate, Obasi y Joiner, 2008), ya que su cohesión y apoyo, aparecen asociados a su bienestar (Birman y Taylor-Ritzler, 2007).

La familia transnacional lo es porque presenta al menos dos núcleos familiares, uno formado por quienes se quedan en el país de origen y otro formado por quienes emigran. Ambos núcleos están interconectados por intercambios de tipo económico, por la comunicación -posible gracias a las nuevas tecnologías- y por vínculos afectivos, pues la separación física no significa una ruptura de las relaciones de dependencia afectiva (Gimeno et al., 2009).

La migración genera nuevos modelos familiares (Martín Fernández, 2006), pero los familiares de una y otra orilla comparten espacios subjetivos: celebraciones, fechas, costumbres, rituales, que les dan sentido de pertenencia y continuidad, fortalecen su identidad de origen y atenúan los sentimientos de pérdida y añoranza.

Abordamos este estudio desde una perspectiva sistémicoecológica (Bronfenbrenner, 2002), diferenciando varias dimensiones de análisis (Espinal, Gimeno y González, 2006; Falicov, 1998; Fishman, 1995): a) Individuos, b) Cultura de origen y de acogida, c) Vida cotidiana, d) Interacciones intrafamiliares y extrafamiliares y e) tiempo, marcado por hitos relevantes (Gimeno et al., 2009).

Nuestra investigación resulta novedosa, porque recoge la perspectiva de las familias en ambas orillas y el testimonio de distintas generaciones, adopta una perspectiva temporal e incluye los escenarios clave del proceso de adaptación: intrafamiliar, laboral, escolar y social. Y precisamente porque incluye el testimonio de los pioneros y de sus familiares directos, es un trabajo útil para "diseñar una gestión adecuada de las migraciones" (Soriano, 2006) y para ofrecer propuestas para la intervención comunitaria y educativa.

Ante las peculiaridades de las migraciones actuales surge la siguiente pregunta, ¿Qué hitos fundamentales se articulan a lo largo de proceso migratorio de las familias colombianas residentes en Valencia, desde la percepción de sus diferentes miembros? De este interrogante derivan los siguientes objetivos: a) identificar los desencadenantes del proceso migratorio, b) conocer las primeras experiencias tras la llegada, c) describir el proceso de adaptación, y su balance en el momento de la entrevista y e) analizar la Aculturación y su influencia en la Educación familiar. 


\section{Método}

\section{Paradigma}

La presente investigación se sitúa en los paradigmas interpretativista y constructivista (González Monteagudo, 2001; Guba, y Lincoln, 1991), ya que la naturaleza del objeto de estudio no se puede abordar directamente, sino que tan sólo se puede interpretar y toda interpretación implica por sí misma una construcción. La metodología interpretativa consiste en analizar las categorías y supracategorías emergentes de las entrevistas grabadas y transcritas, que son las que determinarán los conceptos.

\section{Diseño}

Se plantea un diseño cualitativo basado en la "Grounded Theory" (Glasser y Strauss 1967; Strauss y Corbin, 1990), adecuado cuando se desea analizar unos resultados partiendo de unos objetivos generales, pero sin el sesgo que supone partir de hipótesis previas.

Este enfoque nos permite a) abordar un objeto de estudio complejo -con diversidad de variables y actores-, idiosincrásico e intersubjetivo, b) utilizar las historias de vida, facilitando la libre expresión de los migrantes y desvelar el proceso de construcción social que surge en torno a la migración, c) analizar los datos con rigor, siguiendo un proceso inductivo y un análisis flexible y recursivo, d) integrar las aportaciones de varios investigadores, e) generar una teoría o marco analítico que incremente nuestra comprensión del problema, y f) abrir una vía, a la vez crítica e interpretativa, donde la intrasubjetividad y la intersubjetividad son piezas clave para captar los significados profundos y compartidos de los relatos. Se trata, en suma, de adaptar el método al tema de estudio, desarrollando una metodología propia (Checa y Arjona, 2009).

El análisis de los resultados parte de las expresiones textuales de las entrevistas, hasta lograr una construcción teórica que muestre el significado compartido de la experiencia colectiva. Es un proceso parsimonioso, que fragmenta en unidades de contenido cada relato, agrupándolas luego en categorías, que a su vez se agrupan en categorías más amplias. Se trata de análisis inductivo de abstracción creciente, que permite sistematizar la totalidad de contenidos, mediante el procedimiento de comparación constante, relacionando entre sí las categorías y detectando los temas recurrentes.

\section{Participantes}

Se seleccionaron 31 familias intencionalmente, considerando la riqueza informativa que podían proporcionar. Siete residentes en Colombia con edades entre 28 y 68 años, y 24 residentes en Valencia con edades entre 31 y 59 años. Cuatro varones y 27 mujeres. Estaban laboralmente en activo 24. La ocupación más frecuente era empleada de hogar (50\%), dos mujeres eran odontólogas y el resto tenían trabajos de baja cualificación.
No se pretendió lograr una representación estadística, sino una representación socioestructural o topológica (Bryman, 1988). La selección obedeció a los criterios de variabilidad y de saturación de la información: participantes con suficiente heterogeneidad para obtener información variada y desde distintas perspectivas; el número se cierra cuando la información empieza a ser redundante y ya no aporta datos novedosos.

Se entrevistó a 16 adolescentes, entre 9 y 17 años, residentes en Valencia, cinco eran varones; todos cursaban enseñanza obligatoria y habían nacido en Colombia.

El periodo de permanencia en España osciló entre uno y ocho años.

\section{Procedimiento}

Se buscó en Cali y en Bogotá a familias en las que alguien hubiera emigrado a la Comunidad Valenciana, ambos grupos fueron entrevistados en cada país por colaboradores expertos. El resto de residentes en Valencia procedió de contactos facilitados por la "Asociación Colombiana" y de tres centros educativos públicos, que permitieron conectar respectivamente con padres o hijos, y después con el resto de la familia.

La duración media de las entrevistas fue de 55 minutos, fueron grabadas en audio, previo consentimiento de los entrevistados. Se transcribieron textualmente y se analizaron con el programa Atlas-ti versión 5.1.

\section{Instrumentos}

Se utilizó una entrevista semiestructurada que denominamos La Migración en Tres Tiempos. Aborda sucesos y experiencias pasadas, situación actual y proyectos de futuro. Parte de una narración espontánea y se completa con preguntas relacionadas con los objetivos, adaptadas a cada grupo de entrevistados, padres o hijos.

\section{Resultados}

El sistema de categorías elaborado, nos permite dar respuesta a los objetivos planteados y hacer explícito el imaginario colectivo del proceso migratorio de las familias colombianas, desde las perspectiva de quienes llegaron a España y de quienes quedaron en Colombia.

Tras fragmentar los textos en 1242 citas se sigue un proceso de análisis ascendente, obteniéndose un sistema de categorías formado por 53 códigos, 17 supercódigos y cuatro familias de códigos: Decisión, Inicios, Proceso de adaptación y Aculturación y Educación familiar. Exponemos los datos con apoyo de los mapas conceptuales de cada familia de códigos. Las citas textuales se identifican mediante indicación entre paréntesis de la categoría donde se incluyó la cita y la letra F seguida de un número que identifica a la familia que emitió la cita.

\section{La decisión}

Las citas que dan respuesta al primer objetivo: Conocer los desencadenantes del proceso migratorio, son un total de 92 , 
agrupadas en 13 códigos, y éstos en cuatro supercódigos: Desencadenantes, Facilitadores, Pioneros y Preparativos (Tabla 1), que a su vez están agrupados en la familia que denominamos LA DECISIÓN cuyo mapa se representa en la Figura 1.

Tabla 1

Objetivos con los códigos relacionados

\begin{tabular}{lc}
\hline \multicolumn{1}{c}{ Familias de códigos } & Supercódigos \\
\hline La decisión & $\begin{array}{c}\text { Desencadenantes, Facilitadores, } \\
\text { Pioneros, Preparativos }\end{array}$ \\
92 citas, 13 códigos & Dificultades, Vivencias, \\
Los inicios & Apoyos, Logros \\
180 citas, 16 códigos & Vida familiar, Ámbito laboral, \\
E1 proceso de adaptación & Ámbito escolar, Red social: Padres \\
161 citas, 15 códigos & Balance, Expectativas \\
Aculturación y educación familiar & Importancia de la familia \\
222 citas, 9 códigos & Educación familiar \\
\hline
\end{tabular}

Entre los Desencadenantes diferenciamos los propios del país de origen y los personales. Entre los primeros aparece un conjunto de circunstancias sociopolíticas - en gran medida económicas y laborales - que actúan como efecto empuje de la migración. Los cambios políticos son considerados causa de los problemas sociales y laborales, y de la gran desigualdad social que ha empobrecido a la clase trabajadora. Después llegarían la inseguridad ciudadana y la violencia.

"Llegó un presidente y acabó con el trabajo fijo. Les dio garantías a los empresarios. Entonces las empresas tiraron a toda la gente y metieron microempresas por tres meses, tres meses de trabajo y fuera... (Desencadenante- F1-Padre).

El factor más redundante entre los adultos es el económicolaboral. Los migrantes tienen una escasa cualificación profesio- nal y carecen de experiencia laboral, pero todos esperan encontrar en España un trabajo bien remunerado. Quienes ya poseían trabajo y titulación esperan una oportunidad para ampliar sus horizontes profesionales.

"Iba a ganar mucho dinero sólo con internarme". (Desencadenantes-F7-Madre).

"Tendría trabajo como odontóloga, pero vi que alli no hay futuro" Desencadenantes-F5-Madre).

Los hijos, por el contrario, no hacen referencia a la situación laboral de sus padres, ni a los problemas económicos familiares, pero coinciden con ellos en que la inseguridad ciudadana es un desencadenante:

“..., tú vas por allá y piensas, ¿cuándo me van a robar los zapatos?”. “, ...salía a la calle tenía que ser con alguien, si no prefería quedarme en casa y no salia porque me daba muchisimo miedo. (Desencadenantes-F8-Hijo).

"Nos fuimos a una heladería y había una boda y aqui tienen costumbre de tirar tracas y mi hija pensó que eran disparos y salió corriendo y se abrazó a mí. Ella pensaba que era alguien disparando, porque allá vas por la calle y cuando menos te lo esperas oyes disparos “. (Desencadenantes-F9-Madre).

Entre los Desencadenantes personales surgen sucesos familiares: mujeres solteras con hijos a su cargo, familias desestructuradas, violencia de género, divorcios recientes, soledad y desamor.

"Yo estoy separada con tres hijas...no es fácil afrontar todo". (Desencadenantes-F3-Madre).

España se percibe como un espacio de oportunidades con un idioma común y posibilidades laborales que llevarán a rápidas ganancias (efecto llamada). Estas expectativas coinciden con los cambios legales favorables a la inmigración.

Figura 1

La decisión

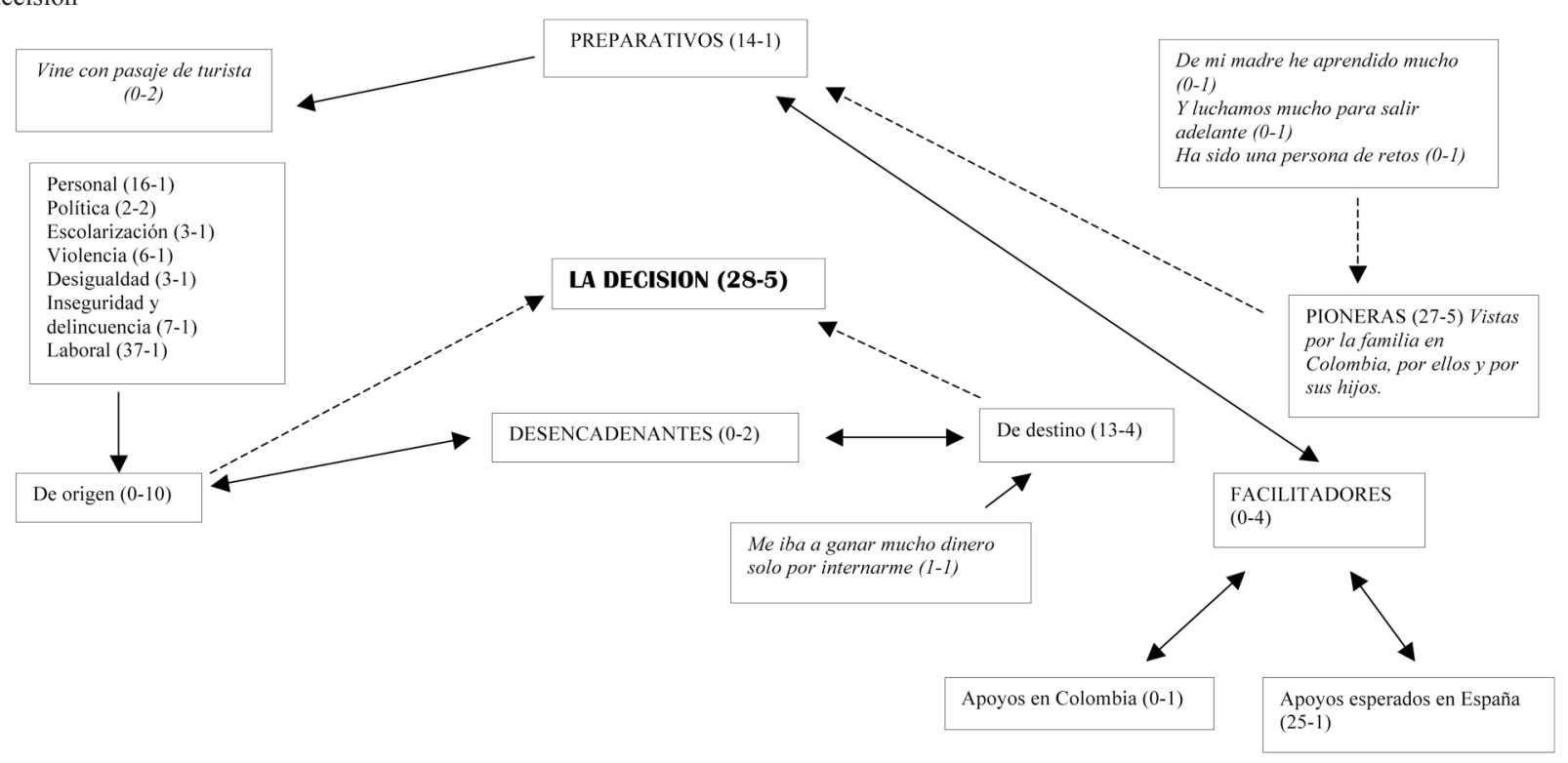


Junto a los factores Desencadenantes encontramos Facilitadores del proceso, como los apoyos que esperan encontrar en España, y los recibidos en Colombia, pues la familia les prestó dinero para el viaje, cuida ahora de sus hijos, les animó a viajar y siempre ha confiado en sus posibilidades de éxito.

"Fue mi padre y también mi madre quien se encargo de la pequeña durante tres años" (Facilitadores F4 Madre). "Mi madre se vino a cuidar de mi hija” (Facilitadores F10-Madre).

En la decisión desempeñan un papel crucial las mujeres: recaban información, deciden y convencen a sus parejas. Muchas veces viajan solas, y siempre son ellas el motor del proceso. Todos han venido sin trabajo y sin permiso residencia.

Los Preparativos se centran en la adquisición del pasaje, además de otras tareas que hemos clasificado como facilitadores. Nadie vino con contrato laboral.

El factor clave de la migración es la personalidad de las Pioneras, mujeres admirables y llenas de cualidades, según la descripción de sus familiares en Colombia y de sus hijos en España. La madre es la persona que admiran y a la que están más estrechamente vinculados.

"Somos demasiado perfeccionistas y muy exigentes con nosotras mismas y luchamos mucho por salir adelante y estar victoriosas en lo que nos proponemos..." (Desencadenantes Personales -F10- Abuela - Colombia).

"Ella nos sacó adelante". "De mi madre he aprendido mucho, me ha enseñado a ser más valiente". "Aunque esté sola, trato de no sentirme cobarde, ni débil por eso soy un poco dura" (Desencadenantes Personales -F11- Hija).

\section{Los inicios}

Respecto al segundo objetivo: conocer las primeras experiencias, encontramos 180 citas, agrupadas en 16 códigos y éstos en 4 supercódigos: Dificultades, Vivencias, Apoyos y Logros (Tabla 1). El mayor número de citas se refiere a las Dificultades, sin duda la fase más dura de la inmigración: viven hacinados, alquilando una habitación a otros inmigrantes y no tienen permiso de residencia, no encuentran apoyo en los contactos que traían. Acceden a trabajos poco cualificados, sueldos bajos y largas jornadas laborales:

"Luego cuando llegas aquí ves que no es todo como le pintan a uno". "Porque cuando estamos en Colombia nos pintaban esto maravilloso. La chica me dijo que yo acá me iba a ganar mucho dinero sólo por internarme (Inicios -F18-Madre).

Las emociones más frecuentes, agrupadas en el código Vivencias, se asocian a frustraciones de todo tipo y especialmente a la añoranza y sufrimiento derivado de la separación, sobre todo de los hijos que quedaron en Colombia.

"Yo sufría mucho por mis niños y mi padre. Llegué a un límite que sufri una depresión”. (Inicios-F18-Madre).

Los hijos que viven en España, sobre todo los mayores, hablan de añoranza hacia sus abuelos, y también de la angustia generada por las dificultades para adaptarse a la escuela, a nivel académico y social. Pero viven también la alegría de la reunificación, considerándola "el mejor regalo" que han recibido de sus padres.

Todos experimentan un cambio cultural que les hace sentirse extraños, de ahí que comparen ambas culturas resaltando

Figura 2

Los inicios.

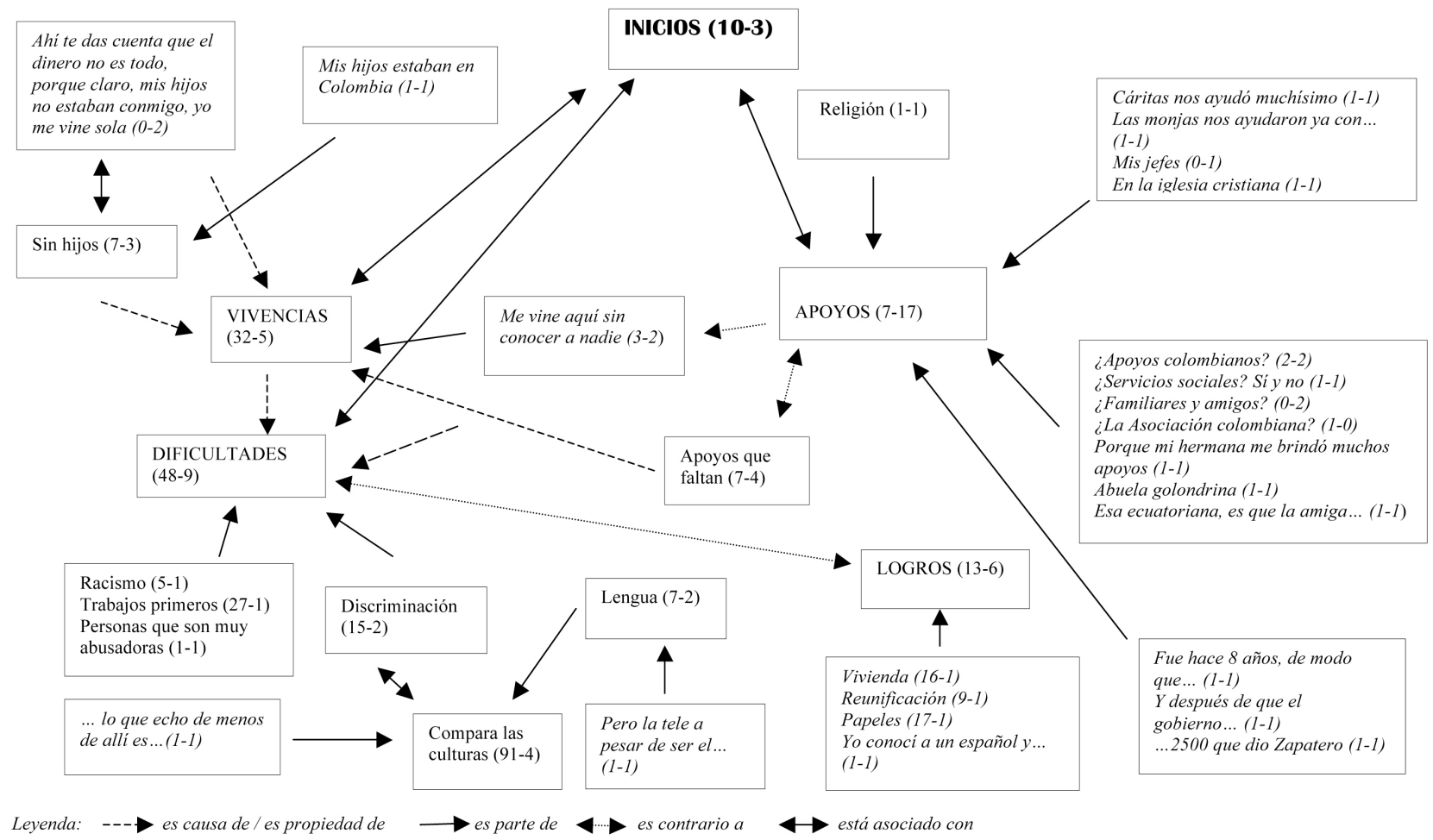


las diferencias y las carencias, referidas a hábitos cotidianos, comidas, música o idioma. Otras diferencias se refieren a rituales y celebraciones; pero fundamentalmente echan de menos a sus gentes, que consideran más comunicativas y afectuosas; frente a los españoles poco acogedores y fríos. Esta es la mayor brecha cultural encontrada en sus relatos.

"Lo que echo de menos de alli es el carisma de la gente. Es gente más abierta y si tú tienes una necesidad se vuelcan en ver cómo te pueden colaborar. Aquí no, aqui tienes una dolencia y sigue cada cual su marcha". (Inicios -F20-Madre).

Otros sufrimientos surgen de problemas personales agudizados por la separación. Encontramos tres casos de divorcio y un caso de violencia que terminó en asesinato de la esposa.

Respecto a los Apoyos a veces fallan los apoyos esperados a su llegada. Pero posteriormente han ido encontrando apoyos decisivos en su proceso de integración social: apoyos de familiares y amigos, apoyos que no esperaban de entidades no gubernamentales, o de sus primeros empleadores, sobre todo en los casos de servicio doméstico y cuidado de ancianos. Los apoyos más controvertidos son los que provienen de servicios sociales y de sus propios compatriotas, que son valorados al mismo tiempo con cordialidad y con desconfianza.

Pero tanto las dificultades como los desengaños les llevan a activar sus propios recursos, su esfuerzo y dedicación sin tregua, para alcanzar las metas que se trazaron, evitando ante todo volver con las manos vacías:

"Ser independiente hizo que saliera adelante...".(Los inicios-F15-Madre).

En consecuencia, poco a poco emergen los primeros Logros, - papeles, trabajos más estables y remunerados, reunificación familiar, vivienda unifamiliar- y viven otros sucesos, que valoran positivamente - primera comunión, bodas o divorcios - .

\section{Proceso de adaptación}

Tras la etapa inicial no carente de dificultades, empiezan con los primeros logros, su proceso de adaptación. Referidas a dicho proceso aparecen 748 citas, agrupadas en 15 códigos y éstos en 6 supercódigos (Tabla 1): Vida familiar, Ámbito laboral, Ámbito escolar, Red social, Balance y Expectativas (Figura 3).

Los cambios en la composición familiar han sido notables. Casi siempre la familia queda reducida a la nuclear, -biparental o monoparental-, que vive en España, aunque también encontramos familias reconstituidas. La familia extensa permanece en Colombia o en otros puntos de España o de Europa. Quedan en Colombia hijos que no van a venir, porque son adultos o porque han quedado bajo la custodia del otro progenitor.

La situación se vive con tristeza y resignación, porque saben que volver atrás es imposible.

"Mi hija vive con su padre porque cuando yo me vine a España ya tenía 2 años y han pasado 7 que estoy aquí.. dice que le gustaría venir a pasear, pero a vivir no porque ella y yo somos como dos extrañas. Si ya cuando traje a la mayor le costó un año adaptarse y eso que llevaba 3 años sin verla, pues la otra que he estado muy poco con ella". (Proceso -F7Madre).

La vida familiar se articula en torno al trabajo, cuyo extenso horario condiciona rutinas cotidianas, el disfrute del tiempo libre y especialmente las relaciones familiares. Todos desean reducirlo para mejorar su calidad de vida.

"Me levanto muy pronto. A las cinco y media o seis máximo ya estoy de pie. Hago cosas de casa y luego me voy a trabajar. A las nueve entro y salgo a la una. No me da tiempo a venir a comer a casa. Por la noche no tengo horario, a veces llego a las nueve..." (Proceso-F9-Madre).

Al regularizar su situación legal mejora el trabajo, aunque siguen preocupados por la falta de estabilidad laboral y por los horarios. La mayoría de mujeres trabajan como empleadas de hogar, al cuidado de ancianos o en la industria alimentaria; los hombres en la construcción y en trabajos de baja cualificación. Definen como muy buena su relación con patronos y compañeros, se sienten valorados en su trabajo y en general satisfechos con sus logros, no tanto por haber alcanzado sus metas, como porque han bajado sus expectativas iniciales aceptando las posibilidades reales.

La incorporación de la mujer al mundo laboral ha cambiado su rol tradicional en la familia, sin que esto se traduzca en mayor igualdad de género respecto a su pareja.

Los hijos, aunque reconocen la importancia de los estudios y asisten regularmente a clase, manifiestan claras dificultades de aprendizaje, pero a pesar de las bajas calificaciones, son optimistas al valorar su rendimiento. Los padres dan pruebas evidentes de interés por sus estudios, valoran bien a los profesores, y al igual que sus hijos los consideran clave en su proceso de adaptación académica y social. En cambio, la relación con los compañeros casi siempre ha empezado con dificultades, indiferencia y hasta rechazo, que se disipan con el tiempo.

La mejora económica incide en la vivienda, pues las familias viven solas en un piso propio, con hipoteca, o alquilado. Todos envían remesas a Colombia.

"Es que ya mi cuñado tenía prácticamente todo adelantado, él tenía un piso que le habían alquilado a él y nos alquiló una habitación. Alli estuvimos viviendo hasta que nos compramos este piso...éste ya es nuestro". (Vida familiar, F4, Madre)

El tiempo libre transcurre compartido con familiares y amigos íntimos, colombianos u otros inmigrantes, y con menor frecuencia españoles, siendo la red social muy reducida. Hacer compras semanales se considera actividad de recreo, mientras el resto del tiempo se pasa en casa. Los hijos comparten el tiempo libre con sus padres, aunque los mayores salen con sus novias o hacen deporte con amigos, pero no pertenecen a pandillas organizadas, tampoco sus padres pertenecen a ninguna asociación. 
Figura 3

El proceso de adaptación.

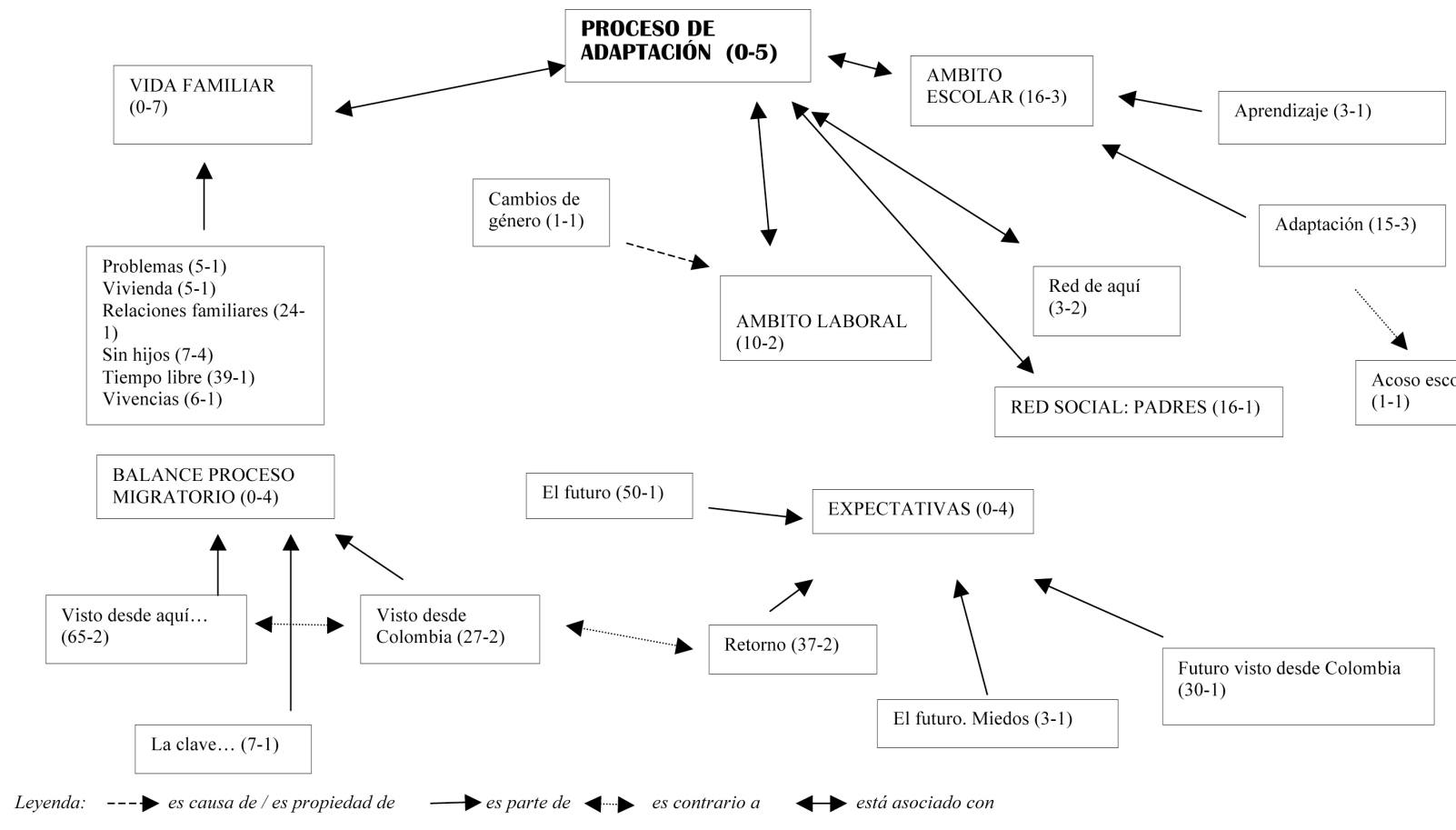

Las vivencias emocionales mejoran, salvo en dos casos de familias que podemos considerar multiproblemáticas, porque acumulan dificultades económicas, hacinamiento, escasa red social, desadaptación escolar y relaciones familiares muy conflictivas:

"Cuando mis hijos llegan yo no estoy y cuando los veo estoy muy estresada porque son muchas horas de trabajo. Tienes muchos problemas y yo no se los puedo contar a ellos". (Adaptación -F8-Madre).

El balance de la migración es claramente favorable cuando evalúan los familiares en Colombia, pero cuando evalúan los migrantes aparecen ambivalencias. Se consideran positivos los logros económicos y laborales, la seguridad ciudadana, pero al tiempo hay un lamento continuo respecto a la escisión familiar y a su integración, pues no se sienten ni aceptados ni valorados por los españoles. De ahí que al mismo tiempo que hablan de permanecer en España, sueñan con el retorno cuando llegue la jubilación. Sólo quienes tienen mejor cualificación profesional y una mentalidad más cosmopolita se ven envejeciendo en España. El éxito de su decisión está en los logros que han conseguido para sus hijos y en el futuro prometedor que les auguran en España, y pensando en ellos creen que todo ha valido la pena.

"Mira, en Colombia se vive muy bien, aqui es más fácil conseguir dinero, en Colombia es más difícil, pero bueno, alli se vive una vida, yo que sé, más suelta”. (Adaptación -F8Madre).

\section{Aculturación y educación familiar}

El cuarto objetivo: Analizar la aculturación y su influencia en la Educación familiar, se refiere a la descripción y valoración de ambas culturas y su influencia en la educación familiar. Incluye 222 citas agrupadas nueve códigos y dos supercódigos: Importancia de la familia y Educación Familiar. El primero incluye: Importancia de la familia desde España, Importancia de la familia desde Colombia, Relaciones con España desde Colombia y Relaciones con Colombia desde España. El segundo, incluye: Comparación cultural, Interculturalidad, Valores familiares y Normas - Contingencias, (Figura 4).

En la Importancia de la familia se insiste desde las dos orillas, explícita o implícitamente, al hacer referencia a los apoyos incondicionales recibidos. Indican que hacia la familia dirigen sus esfuerzos, sus recursos y sus ilusiones, tanto los familiares en Colombia como los de España, adultos e hijos. Consecuencia de ello son las manifestaciones de afecto y el agradecimiento que continuamente manifiestan. Necesitan mantener el contacto con Colombia con frecuencia semanal: por teléfono, mail...., y les envían remesas periódicas, pero sólo excepcionalmente viajan allí. Los vínculos con la familia de origen son muy sólidos y la distancia los ha revalorizado. No obstante, hay historias que incluyen frecuentes conflictos de pareja, divorcios y separaciones, que han dado lugar a familias monoparentales. En definitiva, nos encontramos ante una familia intergeneracional que fortalece con afecto los vínculos de sangre, dejando en un lugar secundario a los cónyuges. 
"....y desde que estoy aquí ya mi hija estudia en la Universidad de Colombia. Le he podido pagar la carrera, a mi madre también le ayudo. Quería un mejor futuro para ellas y me ha tocado sacrificarme". (Educación familiar, F4, Madre)

En Educación familiar se agrupan citas que indican que es ésta una responsabilidad que todos los entrevistados adultos defienden con ahínco, independientemente de su nivel social. Tratan de transmitir a sus hijos sus valores más genuinos: honestidad, obediencia, respeto... e insisten en la importancia del esfuerzo. Todos intentan que sus hijos se impliquen en el estudio. Les preocupan las posibles adicciones al alcohol o al tabaco, y el embarazo precoz de sus hijas. Aunque son muy tolerantes en sexualidad y consideran estas conductas naturales, no descuidan la prevención a pesar de que ven en España menos riesgos que en Colombia.

Comparación cultural, incluye citas referidas a costumbres y valores propios de cada cultura. Indican que la cultura española les era desconocida porque Colombia ha mirado históricamente, no hacia España, sino hacia USA. Se evocan con añoranza las fiestas y celebraciones colombianas, haciendo escasa referencia a las valencianas.

"Sí, alli uno puede colocar su música a todo volumen, aquí uno tiene que vivir como cohibido...". " Aquí pongo música y abro la puerta y ya me están chillando". (Valores, F4, Madre).

Hablan reiteradamente del gran choque cultural que les ha provocado el carácter español, siendo el trato afectuoso con la gente colombiana, la pérdida que más añoran, a pesar de que ahora se sienten más adaptados:

"Alli vas a la calle y ves a mucha gente, te saludan, se hacen amigos. Eso es lo que más echo de menos. Aquí la gente es más cerrada”. (Valores culturales, F7, Madre).
En Interculturalidad incluyen citas sobre sus actitudes y experiencias en el proceso de doble aculturación, valorando y aprendiendo de ambas culturas. Los adultos adoptan la cultura española en los espacios públicos, porque les hace sentirse cómodos, pero mantienen su cultura de origen en el ámbito más íntimo y se sienten claramente colombianos. La mayoría resalta las diferencias entre ambas culturas que consideran diferentes y pocas veces irreconciliables:

"En mi casa me siento colombiano, pero en mi trabajo, español”. (Comparación cultural, F8, Madre).

Hombres y mujeres valoran de la cultura española la seguridad ciudadana, las posibilidades de trabajo y de estudio, el Estado de Derecho. No observamos en sus relatos que hayan logrado unos roles de género equitativos, pero las mujeres indican que el trabajo y su vida aquí han incrementado sus competencias y se sienten más libres, seguras y respetadas, y menos objeto de deseo sexual.

"Alli, una va a un bar y la miran, los españoles son más formales" (Valores culturales, F2, Padre).

La aculturación española es superior entre los hijos, en el ámbito público y privado, unido a su contundente deseo de permanecer en España, y con menos preocupación que los padres por perder sus raíces:

"Mis hijas ahora tienen más bien de aqui que de allá. Pero de todas maneras uno siempre está inculcando lo nuestro. Ellas son como una mezcla, aqui en casa es lo nuestro. Yo creo que ellas ya perderán sus raíces." (Valores culturales y educación -F8-Madre)

Llama la atención que en Normas-contingencias educativas, incluyen múltiples tareas domésticas asignadas a los hijos, pero no aparecen normas explícitas sobre horario de estu-

\section{Figura 4}

Aculturación y educación familiar.

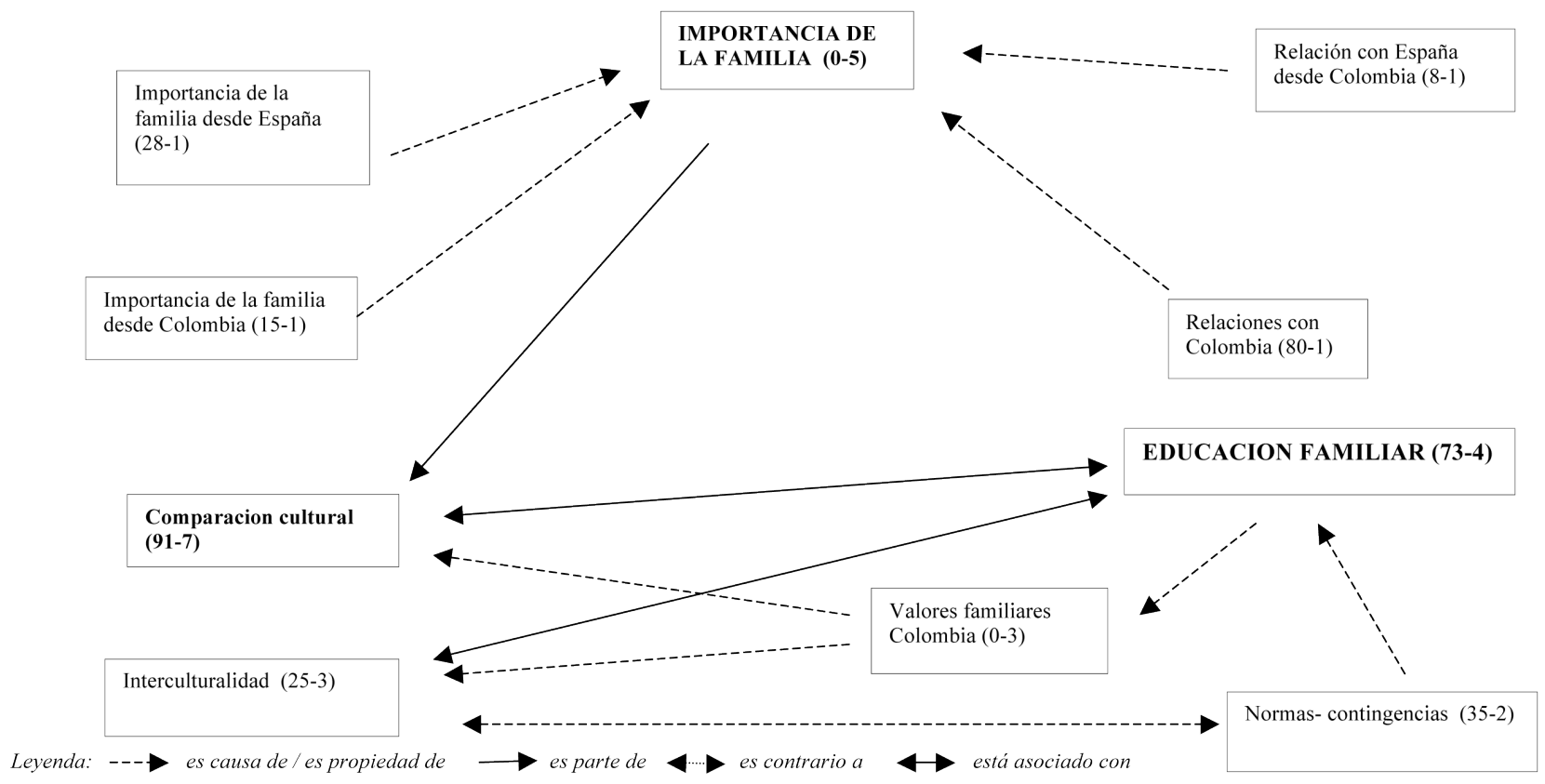


dios. Los hijos perciben una disciplina más punitiva que los padres.

Los padres reconocen que su cultura de origen propicia un estilo educativo más rígido y punitivo, encuentran la educación española más permisiva y democrática, y lo valoran, por eso tratan de suprimir el castigo físico - cachetada, nunca palizas- $y$ usan más las regañinas y la privación de privilegios. Les sirve de modelo el estilo español, por lo que tratan de favorecer la comunicación y la confianza con sus hijos. En cambio, consideran que los hijos españoles han perdido el respeto a sus padres, así como unas normas básicas de educación manifiestas en un lenguaje plagado de palabrotas. En general hay una buena relación entre padres e hijos, siendo las madres la principal figura de apego y admiración.

"En Colombia si que pegaba pero aqui no, porque son más mayores y aquí como vean que a uno se le está pegando una colleja, ya te están denunciando. Suelo castigarlos más bien, no les dejo salir o les quito lo que más les gusta”. (Valores culturales y educación -F16-Madre).

\section{Comparación entre padres e hijos}

Esta comparación no surgió como objetivo explícito pero constituye un resultado de interés.

Observamos que, aunque la Decisión de migrar se hace pensando en los hijos, sus voces no se incluyen en ninguno de los relatos. También aparecen diferencias en Desencadenantes, los Inicios, algunas características del Proceso de Adaptación y su percepción de la Educación familiar (Tabla 2). No obstante, conviene resaltar que las diferencias no se han asociado en ningún caso a conflictos familiares.

\section{Discusión}

El efecto empuje y llamada (Herrera, 2003; Soriano, 2006) del proyecto migratorio se configura en los migrantes colombianos por una combinación de desencadenantes sociales en el país origen y por la percepción de España como un país con posibilidades laborales, de desarrollo y con una legislación favorable a la inmigración. El idioma común contribuye a la decisión, pero los migrantes no hablan de una cultura afín como factor llamada, pues desconocen las costumbres españolas antes de salir. Su proceso no es ajeno a un momento histórico como el actual, caracterizado por los grandes movimientos migratorios.

La red familiar resulta crucial para emprender el proyecto migratorio (Blat, 2006; Colectivo Ioé, 2002). Este se hace realidad gracias al empuje y la tenacidad de los pioneros, mayoritariamente mujeres, que anhelan un futuro mejor para toda la familia y especialmente para sus hijos. Tienen perfiles muy variados (Checa y Arjona, 2009; Díez, 2006) como también son variados los modelos familiares de procedencia.

Los inicios fueron arduos ya que todos los entrevistados viajaron sin papeles. Pero cuando el mito de Europa se desvanece y las metas se hacen más realistas, saben afrontar las dificultades y despliegan sus competencias y esfuerzo para proporcionar a toda la familia una vida más digna. Esta esperanza es su principal motor y su mayor recompensa.

El permiso de residencia ha sido el hito que cambió sus vidas, permitiéndoles en un máximo de ocho años mejorar sustancialmente sus condiciones de vida. Otro hito importante es la reunificación familiar.

El choque cultural procede fundamentalmente de la acogida distante de los españoles, que acrecienta su añoranza y

Tabla 2

Proceso migratorio. Comparación entre padre e hijos

\begin{tabular}{|c|c|}
\hline Padres & Hijos \\
\hline \multicolumn{2}{|c|}{ Desencadenantes } \\
\hline $\begin{array}{l}\text { Circunstancias sociopolíticas origen de problemas sociales y laborales. } \\
\text { Inseguridad ciudadana y violencia. } \\
\text { Afrontamiento de la maternidad en solitario, violencia de género }\end{array}$ & $\begin{array}{l}\text { Inseguridad ciudadana. } \\
\text { Vivir con sus padres. }\end{array}$ \\
\hline \multicolumn{2}{|c|}{ Inicios } \\
\hline $\begin{array}{l}\text { Dificultades (vivienda, papeles, falta de apoyo, malas condiciones laborales...). } \\
\text { Dificultades de aculturación. } \\
\text { Añoranza de los hijos y familia en general. }\end{array}$ & $\begin{array}{l}\text { Dificultades para adaptarse al centro escolar, a nivel académico y social. } \\
\text { Dificultades de aculturación. } \\
\text { Añoranza de sus abuelos. } \\
\text { Alegría de la reunificación: el mejor regalo de sus padres. }\end{array}$ \\
\hline \multicolumn{2}{|c|}{ Proceso de adaptación: Estudios } \\
\hline $\begin{array}{l}\text { Muy interesados por los estudios de sus hijos, valoran bien a los profesores. } \\
\text { Son la clave para mejorar su futuro, ya los cursen aquí o allá. } \\
\text { No hay normas explícitas sobre horario de estudios. }\end{array}$ & $\begin{array}{l}\text { Valoran los estudios, pero suelen tener dificultades de aprendizaje y a veces } \\
\text { dificultades iniciales en la relación con los compañeros, que suelen disiparse con } \\
\text { el tiempo. }\end{array}$ \\
\hline \multicolumn{2}{|c|}{ Proceso de adaptación: Tiempo libre } \\
\hline $\begin{array}{l}\text { Lo dedican a compras y a compartir tiempo con familiares y amigos. } \\
\text { No pertenecen a asociaciones. }\end{array}$ & $\begin{array}{l}\text { Lo comparten con sus padres. } \\
\text { Los mayores también lo hacen con sus novias o con los amigos. } \\
\text { No pertenecen a pandillas organizadas. }\end{array}$ \\
\hline \multicolumn{2}{|c|}{ Aculturación y Educación familiar: Valores } \\
\hline $\begin{array}{l}\text { Valores a transmitir: honestidad, obediencia, respeto, importancia del esfuerzo } \\
\text { Formas disciplinarias: reñir, privar de privilegios, dar una cachetada. } \\
\text { Reconocen que su estilo educativo es más rígido y punitivo que el de los } \\
\text { españoles, que califican de más permisivo y democrático. }\end{array}$ & $\begin{array}{l}\text { Los hijos perciben una disciplina más punitiva por parte de sus padres. } \\
\text { En algunos casos tienen que asumir demasiadas tareas domésticas. }\end{array}$ \\
\hline \multicolumn{2}{|c|}{ Aculturación y Educación familiar: Normas y contingencias } \\
\hline $\begin{array}{l}\text { Fundamentalmente se produce en los espacios públicos. } \\
\text { En lo más íntimo se sienten colombianos. }\end{array}$ & $\begin{array}{l}\text { Superior en los hijos a nivel público y privado } \\
\text { Deseo de permanecer en España. } \\
\text { Menos preocupados que los padres por perder sus raíces. }\end{array}$ \\
\hline
\end{tabular}


su soledad. A nivel individual, aunque los españoles no suelen aparecer entre sus amigos íntimos, se sienten aceptados por aquellas personas con las que han tenido un trato directo, $\mathrm{y}$ les agradecen las ayudas recibidas (Gracia, Herrero y Musitu, 1995). Respecto a sus compatriotas tienen una visión contradictoria, pues son para unos, apoyos y para otros amenaza.

La indiferencia percibida por los inmigrantes nos lleva a reflexionar sobre nuestro etnocentrismo y sutil xenofobia y en esa línea, Ayerdi y Díaz de Rada (2008) constatan un abanico de actitudes que van desde las permisivas y hasta cierto punto solidarias, hasta las de una cierta reticencia hacia la inmigración en España. En nuestro trabajo se percibe una evolución desde la frialdad antes de conocerlos, al apoyo brindado en el cara a cara. Esta realidad urge a plantear políticas sociales y educativas, centradas en la tolerancia intercultural, por dos razones: una ética, lograr que los derechos humanos no tengan fronteras, y otra empática, evitar el sufrimiento de quienes no eligieron su lugar de nacimiento, pero sí que han elegido convivir con nosotros.

Como el trato directo reduce nuestra indiferencia, parece obvio que estas políticas sociales deben favorecer la convivencia intercultural, evitando a toda costa los prejuicios y las amenazas. Una organización social centrada en los derechos humanos y un auténtico modelo de convivencia es el legado que deberíamos aportar a los inmigrantes.

El balance global es positivo, aunque la realidad no coincide con las expectativas que forjaron. Han mejorado, pero a un coste muy elevado, con pérdidas irreparables a nivel personal. Quizá, como indica Ruiz (2002), en la actualidad no hay ni sueño, ni pesadilla. Entre lo positivo cuenta la organización social del país: laboral, educativa, sanitaria, asistencial, etc. Pero sobre todo, el argumento que inclina la balanza es la esperanza de una vida mejor para sus hijos, porque algunos de ellos piensan en regresar tras la jubilación.

Entre los adultos podemos hablar de una doble aculturación (Berry, 1992), más colombiana en el terreno de lo privado y española en el ámbito público. Los hijos tienen sus raíces en España y quieren permanecer en la sociedad receptora, les gusta el país, han asimilado la cultura a gran velocidad, superando las dificultades iniciales académicas y de socialización, y se van desvinculando de los contactos con la familia de Colombia.

Los hijos viven su propio proceso migratorio, que iniciaron con el logro de la reunificación familiar. Ahora están viviendo el proceso de adaptación a la escuela y a la sociedad, pero progresan rápido, aunque en algunos casos tienen problemas en la escuela o tienen que realizar demasiadas tareas domésticas debido a la extensa jornada laboral de sus madres. No se han detectado conflictos intergeneracionales causados por el diferente nivel de aculturación entre padres e hijos.

La familia extensa, la institución en torno a la que gira la vida del colombiano, defiende valores como la obediencia, respeto a los mayores, responsabilidad e interés por sus estudios. Predomina un estilo educativo autoritario, que evoluciona hacia posiciones más dialogantes, menos punitivas, aprendidas de la cultura española.

Sus redes sociales, poco desarrolladas, están formadas prioritariamente por familiares. No pertenecen a ninguna asociación, ni con fines políticos ni sociales, tampoco hay indicadores de participación en ningún proyecto colectivo o acción social, ni aquí ni en Colombia. Su proyecto vital queda centrado en la familia. Es probable que arrastren desde Colombia el desamparo aprendido hacia lo comunitario, pero esta desesperanza puede ser una limitación que les impida lograr un reconocimiento de sus derechos como ciudadanos, tanto aquí como allí. Los relatos colombianos de autocrítica, insisten en la falta de proyectos comunitarios que mejoren la vida en Colombia, tarea que deberían liderar quienes regresan.

Es importante que en estudios futuros se profundice sobre el fracaso en la consecución de una igualdad de género, porque ni la iniciativa femenina en la migración, ni la incorporación de la mujer al trabajo, parecen haber facilitado el camino hacia la igualdad de género. Las mujeres encuentran trabajos de baja cualificación y mantienen el doble rol de mantenedoras y cuidadoras, con sobrecarga de roles y tareas; conocen mejor sus derechos, pero no los ejercen. Nuestros resultados son menos optimistas que los aportados por Soriano (2006) respecto a los inmigrantes mejicanos en USA y más cercanos de la triple marginación - mujer, inmigrante y trabajadora precaria- mencionada por Parella (2003). Las parejas que valoran y viven la igualdad, lo hacen por su formación previa, no por influencia de la aculturación española. Constituyen familias de riesgo en nuestro estudio las formadas por mujeres solas, sin estudios ni cualificación profesional y con pocos recursos.

El proceso analizado queda incompleto sin el testimonio de quienes regresaron con las manos vacías, o insatisfechos tras la crisis económica. También es necesario el testimonio de quienes aún no han emigrado, pero estarían dispuestos a hacerlo tal como alude el trabajo de Masanet (2008).

Los testimonios recogidos apuntan a la necesidad de revisar no sólo las políticas de acogida a los inmigrantes, sino sobre todo de lograr un reparto más equitativo de los recursos del planeta, evitando la explotación que empobrece y genera una emigración forzosa. Entre tanto, como indica Soriano (2006) son necesarias políticas sociales que respeten los derechos y la dignidad de los inmigrantes, especialmente de las mujeres y que faciliten la integración de los menores. Especialmente ahora que somos tanto país de destino como país de partida no podemos mirar hacia otro lado.

\section{Referencias}

1. Achotegui, J. (2008). Migración y crisis: el síndrome del inmigrante con estrés crónico y múltiple (síndrome de Ulises). Avances en Salud Mental Relacional 7(1). Revista Internacional On-Line. Recuperado de http://www.bibliopsiquis.com/asmr/numeros.htm

2. Araujo, Z. (1996). Portuguese families. En M. McGoldrick 
y J. Giordano (Ed), Ethnicity and familiy therapy (pp. 583594). New York: Ayri.

3. Ayerdi, P. y Díaz de Rada, V. (2008). Perfiles sociales de la opinión pública española sobre la inmigración. Revista Internacional de Sociología, (RIS) LXVI, 95-127.

4. Berry, J. (1992). Acculturation and adaptation in a new society. International Migration, 30, 69-86. http:// dx.doi.10.1111/j.1468-2435.1992.tb00776.x

5. Berry, J. W. (1998). Conceptual approaches to understanding acculturation. International conference in Acculturation: Advances in Theory Measurement and Applied Research. San Francisco, USA: University of San Francisco.

6. Bettio, F., Simonazzi, A., Solinas, G. y Villa, P. (2004). The "Care Brain" in the Mediterranean: notes on the italian experience. Conference of the International working Party on Labour Market Segmentation, Brisbane. Australia.

7. Birman, D. y Taylor-Ritzler, T. (2007). Acculturation and psychological distress among adolescent immigrants from the former Soviet Union: Exploring the mediating effect of family relationships. Cultural Diversity and Ethnic Minority Psychology, 13, 337-346. http://dx.doi.10.1037/10999809.13.4.337

8. Blat, A. (2006). Actitudes ante la escolarización de menores de origen extranjero en la Comunidad Valenciana. (Directores de centros, profesores y padres). CEIM: Valencia. Recuperado de http://www.ceimigra.net/viejaweb/ ceim home/explication.htm.

9. Bronfenbrenner, U. (2002). La ecología del desarrollo humano. Experimentos en entornos naturales y diseñados. Barcelona: Paidós.

10. Bryman,A.(1988).Quantity and qualityin research.London: Rouletge. http://dx.doi.org/10.4324/9780203410028

11. Castella, J. (2003). Estudios actuales sobre aculturación en Latinos. Resumen y nuevas perspectivas. Revista Internacional de Psicología, 37, 341-364.

12. Checa, J.C. y Arjona, A. (2009). La integración de inmigrantes de segunda generación en Almería. Un caso de pluralismo fragmentado. Revista Internacional de Sociología (RIS), 67, 701-727. http://dx.doi.10.3989/ris.2008.04.17

13. Colectivo IOÉ (2002). ¿Cómo abordar el estudio de las migraciones? Propuesta teórico-metodológica. En F. Checa (Ed.), Las migraciones a debate. De las teorías a las prácticas sociales (pp. 17-54). Barcelona: Icaria.

14. Díez, A. (2006). Análisis de la migración colombiana en España. Volumen y perfil sociodemográfico de la inmigración colombiana en Sevilla: 1995-2004. Tesina para la obtención del DEA no publicada. Sevilla: Universidad de Sevilla.

15. Dovidio, J. F., Gaerter, S. L. y Validwzic, A. (1998). Intergroup bias: Status, differentiation, and a common in group identity. Journal of Personality and Social Psychology, 75, 109-120. http://dx.doi.org/10.1037/0022-3514.75.1.109
16. Eisikovits, R. (2000). Gender and Cultural Adaptation in Immigrant Families. Journal of Social Issues, 57, 511-521. http://dx.doi.10.1111/0022-4537.00226

17. Espinal, I. Gimeno, A. y González, F. (2006). El enfoque sistémico en los estudios sobre la familia. Revista Internacional de Sistemas, 14, 21-35.

18. Escobar, J. y Vega, W.A. (2000). Mental health and immigration's. Journal of Nervous and Mental Disease, 188, 736-740. http://dx.doi.10.1234/12345678

19. Falicov, L. (1998). Latino families in therapy: A guide to multicultural practice. New York: Guilford Press.

20. Falicov, C. J. (2007). Working with transnational immigrants: Expanding meanings of family, community and culture. Family Process, 46, 157-171. http://dx.doi.10.1111/ j.1545-5300.2007.00201.x

21. Fishman, H. Ch. (1995). Tratamiento de adolescentes con problemas. Barcelona: Paidós.

22. Gimeno, A., Lafuente, M.J., González; F., Bolaños, L.M., Echevarría, M. y Parra, G. (2009). Familias transnacionales colombianas: nivel de aculturación y vida familiar vistas desde las dos orillas. Cuadernos de Investigación, 9. Valencia: Tirant lo Blanch.

23. Glasser, B. G. y Strauss, A. (1967). The discovery of grounded theory. Chicago: Aldine.

24. González Monteagudo, J. (2001). El paradigma interpretativo en la Investigación Social y Educativa. Cuestiones Pedagógicas. 15, 227-246

25. Guba, E.G. y Lincoln Y.S. (1991). Investigación naturalista y racionalista. En T. Husen y T.N. Postlethwaite (Eds), Enciclopedia Internacional de la Educación (pp. 33373343). Barcelona: Vicens Vives MEC.

26. Gracia E., Herrero J. y Musitu G. (1995). El apoyo social. Barcelona: P.P.U.

27. Henao, C.L. (2008). Continuidad y cambio en los valores, concepciones y prácticas de socialización en familias inmigradas de origen latinoamericano en Barcelona. Tesis Doctoral. Barcelona: Universitat Autònoma de Barcelona.

28. Herrera, G. (2003). La migración vista desde el lugar de origen. Iconos, 15, 86-94.

29. Magaña, J.R., De la Rocha, O., Amse, J. y Magaña, H. (1996). Revisiting the dimensions of acculturation: Cultural Theory and Psychometry practice. Hispanic Journal of Behavior Sciences, 18, 444-468. http://dx.doi. org/10.1177/07399863960184002

30. Martín Fernández, C (2006). Familia y migración internacional: dinámicas transnacionales y transfamiliares en la cotidianidad de los países emisores. Recuperado de www. uh.cu/centro/cemi/anuario/trabajo\%20/4familia/pdf.

31. Martínez, M.C., Paterna, C., López, J. A. y Martínez, J. (2007): Autoestima colectiva y aculturación en inmigrantes ecuatorianos». Apuntes de Psicología, 25, 67-78.

32. Masanet, E. (2008). De Brasil a España: un estudio sobre la migración desde una perspectiva integrada de los luga- 
res de origen y destino. Tesis Doctoral. Alicante: Universidad de Alicante.

33. Nette, J. y Hayden, M. (2007). Globally mobile children: the sense of belonging. Educational Studies, 33, 435-444. http://dx.doi.10.1080/03055690701423614

34. Parella, S. (2003). Mujer, inmigrante y trabajadora: la triple discriminación. Barcelona: Anthropos.

35. Parella, S. (2007). Los vínculos afectivos y de cuidado en las familias transnacionales. Migrantes ecuatorianos y peruanos en España. Migraciones Internacionales, 4, 152188.

36. Pedone, C. (2005) Relazioni di genere e catene familiari in un contesto migratorio internazionale. En: M. Ambrosini y L. Queirolo Palmas (Eds.), Il Latinos alla scoperta dell'Europa. Nuove migrazioni e spazi della cittadinanza (pp. 32-65). Milán: Editorial Fratelli.

37. Pedone, C. (2006). Los cambios familiares y educativos en los actuales contextos migratorios ecuatorianos: una perspectiva transatlántica. Athenea Digital, 10, 154-171. Recuperado de http://antalya.uab.es/athenea/num10/pedone.pdf

38. Pollock, D. y Van Reken, R. E. (1999). The third culture kid experience: growing up among worlds. Yarmouth, MA: Intercultural Press.

39. Portes, A. y Zhou, M. (1993). The New Second Generation: Segmented Assimilation and Its Variants. The Annals of the American Academy of Political and Social Sciences, 530, 74-96. http://dx.doi.10.1177/0002716293530001006

40. Ruiz C. (2002). Ni sueño ni pesadilla. Diversidad y paradojas en el proceso migratorio. Revista de Ciencias Sociales, 14, 88-97. Recuperado de http://www.redalyc.org/articulo. $\underline{\text { oa? } \mathrm{id}=50901408}$
41. Sorensen, N. (2005). Transnational family life across the Atlantic: The experience of Colombian and Dominican migrants in Europe. Ponencia presentada en International Conference on Migration and Domestic Work in Global Perspective, 26-29 Mayo Wassernar, Países Bajos.

42. Soriano, R. M. (2006). Voces de mujeres desde la inmigración: una comparativa entre el asentamiento de marroquíes en España y mexicanas en USA. Working Paper, 133. The Center for Comparative Immigration Studies (CCIS). University of California, San Diego.

43. Strauss, A. y Corbin, J. (1990). Basics of Qualitative Research: Grounded Theory, Procedures and Techniques. Newbury Park, Ca: Sage Publications.

44. Sluzki, C. E. (1996). La red social, frontera de la práctica sistémica. Barcelona: Gedisa.

45. Walker, R. L., Wingate, L. R., Obasi, E. M. y Joiner, T. E. (2008). An empirical investigation of acculturative stress and ethnic identity as moderators for depression and suicidal ideation in college students. Cultural Diversity and Ethnic Minority Psychology, 14, 75-82. http:// dx.doi.10.1037/1099-9809.14.1.75

46. Wolsko, C., Park, B., Judd, C. M. y Wittenbrink, B. (2000). Framing interethnic ideology: Effects of multicultural and colour-blind perspectives on judgements of groups and individuals. Journal of Personality and Social Psychology, 78, 635-654. http://dx.doi.10.1037/0022-3514.78.4.635

Fecha de recepción: 20 de junio de 2013 Fecha de recepción de la versión modificada: 15 de octubre de 2013 Fecha de aceptación: 21 de noviembre de 2013 